Research Article

\title{
Study of Thermomechanical Properties of an Al-Zn-Based Composite Reinforced with Dodecaboride Particles
}

\author{
José Luis Colón Quintana $\mathbb{D}^{1},{ }^{1}$ Sujeily Soto Medina $\mathbb{D}^{2},{ }^{2}$ Marivic Hernández, ${ }^{3}$ and \\ Oscar Marcelo Suárez $\mathbb{1}^{4}$ \\ ${ }^{1}$ Polymer Engineering Center, Department of Mechanical Engineering, University of Wisconsin-Madison, Madison, \\ WI 53706-1691, USA \\ ${ }^{2}$ Department of Materials Science and Engineering, University of Florida, Gainesville, FL 32611, USA \\ ${ }^{3}$ Department of Mechanical Engineering, University of Puerto Rico-Mayagüez, Mayagüez, PR 00681-9000, USA \\ ${ }^{4}$ Department of Engineering Science and Materials, University of Puerto Rico-Mayagüez, Mayagüez, PR 00681-9000, USA
}

Correspondence should be addressed to José Luis Colón Quintana; colonquintan@wisc.edu

Received 12 June 2017; Revised 19 October 2017; Accepted 21 November 2017; Published 14 February 2018

Academic Editor: Alexander Pyatenko

Copyright ( 2018 José Luis Colón Quintana et al. This is an open access article distributed under the Creative Commons Attribution License, which permits unrestricted use, distribution, and reproduction in any medium, provided the original work is properly cited.

\begin{abstract}
The effect of the addition of $\mathrm{AlB}_{12}$ particles to gravity cast $\mathrm{Al}-\mathrm{Zn}$ alloys was studied and related to the composite deformation at high temperature. The characterization techniques of choice were thermomechanical analysis (TMA), Brinell hardness (HB), and optical microscopy. After homogenization treatment, Al-5 wt.\% Zn and Al-10 wt.\% Zn with 0, 2.08, 4.16 wt.\% B samples were quenched in ice water and tested using a thermomechanical analyzer at different temperatures. It was found that after TMA treatment, Brinell hardness of the composites increased for higher concentrations of zinc and $\mathrm{AlB}_{12}$ particles, as expected. Such increment was not, however, uniform for all samples at higher temperature levels, suggesting a nonequilibrium interaction between reinforcing particles and zinc. This was further corroborated by TMA experiments, which revealed that for samples with Al-10 wt.\% Zn, high temperature deformation augmented as more $\mathrm{AlB}_{12}$ particles were present. After high temperature treatment, precipitation of zinc-rich allotriomorphs was observed by the optical microscopy performed on the samples near or on the aluminum grain boundaries, which discarded the potential effect of fine precipitation due to aging.
\end{abstract}

\section{Introduction}

Cast aluminum matrix composites have been widely used in the automotive and aerospace industry due to their weightto-strength ratio [1-5]. Because of such application of these types of composites, studying their behavior at high temperatures is mandatory. Researchers demonstrated that the addition of hard boride particles to an aluminum matrix can enhance the composite strength. For instance, $\mathrm{AlB}_{2}$ particles are an alternative to $\mathrm{SiC}$ reinforcement particles in aluminum [6], particularly because $\mathrm{SiC} / \mathrm{Al}$ composites can have inconsistent wear resistance. This behavior has been attributed to the weak interface between $\mathrm{SiC}$ and the $\mathrm{Al}$ matrix [7] with potential deleterious aluminum carbide formation.

By adding hard boride particles to an $\mathrm{Al}$ matrix, the wear rate of the composite is lower when compared to unreinforced aluminum [2]. In effect, prior studies of $\mathrm{Al}-\mathrm{Cu}$ alloys reinforced with $\mathrm{AlB}_{2}$ particles embedded in the matrix demonstrated that diboride contributed to increase effectively the material stiffness [8] with a subsequent ductility loss in the composite. A weak particle/matrix in these composites is a nonissue since it has been reported that the $\mathrm{AlB}_{2}$ particles can serve as nucleation sites of aluminum upon solidification, which is associated with a low interfacial energy between liquid $\mathrm{Al}$ and $\mathrm{AlB}_{2}$ [6]. For structural applications, alloying metals in the aluminum matrix are a necessity to calibrate the final mechanical properties of the material. In particular, Al-Zn-based alloys are amongst the strongest aluminum alloys. For instance, Al alloys bearing up to $30 \mathrm{wt} . \% \mathrm{Zn}$ can attain discontinuous precipitation at $75^{\circ} \mathrm{C}, 100^{\circ} \mathrm{C}$, and $150^{\circ} \mathrm{C}$ [9]. Such precipitation of a second phase improves hardness, Young's modulus, and yield 
TABLE 1: Master alloys' chemical composition.

\begin{tabular}{lcccrr}
\hline & \multicolumn{2}{c}{ Composition } & & \multicolumn{2}{c}{ Master alloys } \\
Wt.\% Zn & Wt.\% B & Particle volume fraction & Al-95 wt.\% Zn (g) & Al-5 wt.\% B (g) & 0 \\
\hline 5 & 0 & 0 & 0.631 & 5 & 11.368 \\
5 & 2.08 & 0.165 & 0.631 & 6.568 \\
5 & 4.17 & 0.225 & 0.631 & 10 & 1.768 \\
\hline 10 & 0 & 0 & 1.263 & 0 \\
10 & 2.08 & 0.165 & 1.263 & 5 \\
10 & 4.17 & 0.225 & 1.263 & 10.737 \\
\hline
\end{tabular}

strength of the alloy. Controlled Zn precipitation occurs because of age hardening when precipitation treatment was performed at those low temperatures followed by fast cooling to avoid forming more stable and larger precipitates. Naturally, the resulting microstructure and properties vary and depend on the effectiveness and details of the heat treatment. For this reason, we propose using a $\mathrm{Zn}$ containing $\mathrm{Al}$ matrix reinforced with hard aluminum dodecaboride particles, which a prior research proved to strengthen aluminum solid solution matrices [10].

To this purpose, we added $\mathrm{AlB}_{12}$ particles at different levels into an $\mathrm{Al}$ matrix containing $5 \mathrm{wt} . \% \mathrm{Zn}$ and $10 \mathrm{wt} . \% \mathrm{Zn}$ as an alternative to other aluminum matrix composites. A thermomechanical analysis (TMA) apparatus, commonly used in the polymer composite field to measure mechanical strength as a function of temperature [11], allowed studying how the composite behaves when subject to high temperatures and heat treatments under compressive loads as done for powder titanium composites [12]. Further mechanical and metallographic characterization included Brinell hardness and optical microscopy.

\section{Experimental Procedure}

2.1. Sample Preparation. The target chemical composition of the samples was reached by using master alloys bearing $\mathrm{Al}-$ 95 wt.\% Zn, Al-5 wt.\% B (containing boron as $\mathrm{AlB}_{12}$ particles), and aluminum pellets with $99.99 \%$ purity. The weighted amounts from each master alloy were calculated according to Table 1 to obtain concentrations of Al-5 wt.\% $\mathrm{Zn}$ and $\mathrm{Al}-10$ wt.\% $\mathrm{Zn}$ with 0, 2.08, and 4.17 wt.\% B. The corresponding boride volume fraction in the table was computed based on metallographic measurements provided by Melgarejo et al. [2] in a prior research.

All samples were melted at $760^{\circ} \mathrm{C}$ in an electric furnace and held at that temperature for 5 minutes for homogenization purposes. At half the holding time, the melt was stirred using a graphite stirrer preheated at $426.7^{\circ} \mathrm{C}$ to homogenize the melt further. One should note that the $\mathrm{AlB}_{12}$ particles remained solid during the entire process as demonstrated by preliminary experimentation and prior research by Adelakin [10]. The molten composite was poured into a graphite mold. Each ingot was cut into cubic specimens approximately $5 \times 5 \times 5 \mathrm{~mm}$ using a precision slow saw blade and then polished. The composite specimens were solution treated at $500^{\circ} \mathrm{C}$ for 20 minutes in an electrical furnace, followed by quenching into ice water. All specimens
TABLE 2: TMA treatment temperatures for each concentration.

\begin{tabular}{lccc}
\hline Composites' nominal composition & \multicolumn{3}{c}{ TMA temperatures } \\
with aluminum as balance & $125^{\circ} \mathrm{C}$ & $160^{\circ} \mathrm{C}$ & $200^{\circ} \mathrm{C}$ \\
\hline 5 wt.\% Zn, 0 wt.\% B & $\mathrm{x}$ & $\mathrm{x}$ & $\mathrm{x}$ \\
5 wt.\% Zn, 2.08 wt.\% B & $\mathrm{x}$ & $\mathrm{x}$ & $\mathrm{x}$ \\
5 wt.\% Zn, 4.16 wt.\% B & $\mathrm{x}$ & $\mathrm{x}$ & $\mathrm{x}$ \\
\hline 10 wt.\% Zn, 0 wt.\% B & $\mathrm{x}$ & $\mathrm{x}$ & $\mathrm{x}$ \\
10 wt.\% Zn, 2.08 wt.\% B & $\mathrm{x}$ & $\mathrm{x}$ & $\mathrm{x}$ \\
10 wt.\% Zn, 4.16 wt.\% B & $\mathrm{x}$ & $\mathrm{x}$ & $\mathrm{x}$ \\
\hline
\end{tabular}

were stored in a freezer for 2 to 7 days to avoid natural aging before the TMA experiments.

2.2. Thermomechanical Analysis. TMA/SDTA $841^{e}$ (MettlerToledo AG, Analytical, Switzerland) was used for the thermomechanical studies. For this experiment, the cubic samples were heated to a preset constant temperature, as shown in Table 2, and held at that temperature for 1 hour while a constant compression force of $1 \mathrm{~N}$ was applied using a cylindrical quartz probe with a flat cap $3 \mathrm{~mm}$ in diameter. This resulted in a constant compressive stress of $141.47 \mathrm{kPa}$ on the samples for the entire run of the TMA experiment. The instrument recorded the sample deformation due to the applied load as a function of time during the entire experiment. Negative values are as a result of the compressive test.

After one hour of this heat treatment, the load was removed and the samples were slowly cooled at $2^{\circ} \mathrm{C} / \mathrm{min}$ to replicate annealing conditions. We computed the deformation of every sample upon loading by subtracting the final thickness $\left(t_{f}\right)$ from the initial thickness $\left(t_{i}\right)$, as shown in the following equation:

$$
\text { Deformation }=t_{f}-t_{i}
$$

2.3. Brinell Hardness. After the TMA experiments, the superficial Rockwell hardness tests were performed on all slowly cooled samples, as we were limited by the small specimen size. Hardness measurements with a $1.5875 \mathrm{~mm}$ steel ball indenter were performed onto two parallel, opposed surfaces of each sample. An inverted optical microscope model Nikon EPIPHOT 200 (Nikon Instruments Inc., NY, USA) operated at $5 \mathrm{x}$ magnification was allowed for measuring the 

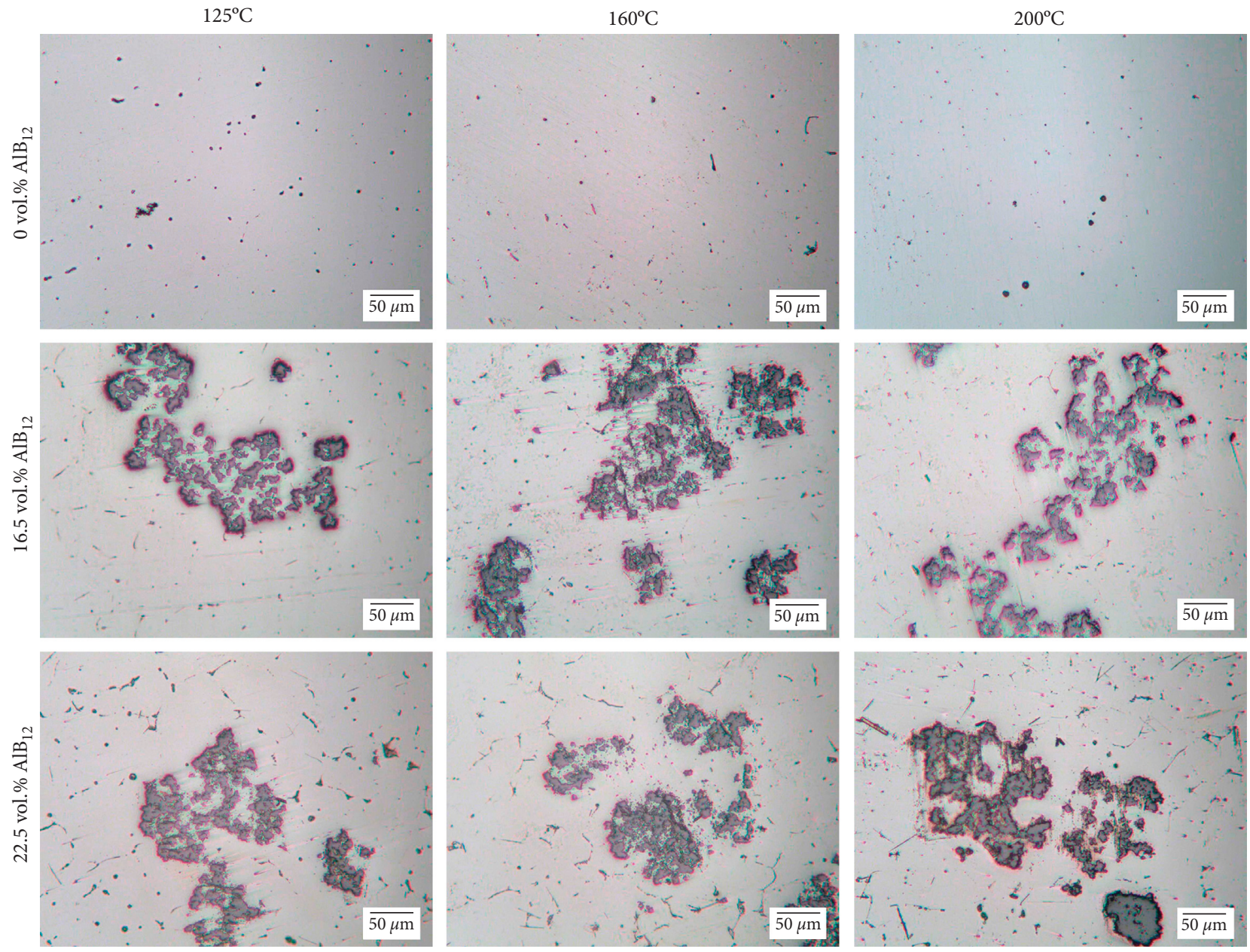

Figure 1: Optical micrographs for $\mathrm{Al}-5$ wt. $\% \mathrm{Zn}$ samples containing $0,16.5$, and 22.5 vol. $\% \mathrm{AlB}_{12}$ after treatment at $125^{\circ} \mathrm{C}, 160^{\circ} \mathrm{C}$, and $200^{\circ} \mathrm{C}$ followed by slow cooling.

indentation size with ImageJ public domain image analysis. After measuring each area, the Brinell hardness in $\mathrm{GPa}$ was calculated using the well-known following equation:

$$
\mathrm{BHN}=\frac{2 P}{\pi D\left(D-\sqrt{D^{2}-d^{2}}\right)},
$$

where $P$ is the force applied on the material surface, $D$ is the indenter diameter, and $d$ is the indentation diameter.

2.4. Optical Microscopy. After fine polishing, a $10 \% \mathrm{NaOH}$ solution etching for 30 seconds allowed enhancing the microstructure for metallographic analysis. We used the same inverted optical microscope furbished with a highresolution camera to analyze and photograph the microstructure.

\section{Results}

3.1. Optical Microscopy Observations. Figure 1 displays the resulting microstructure of the $\mathrm{Al}-\mathrm{Zn}-\mathrm{B}$ composite for all levels of dodecaboride volume fraction and treatment temperatures of the $\mathrm{Al}-5 \mathrm{wt} . \% \mathrm{Zn}$ composite. In all

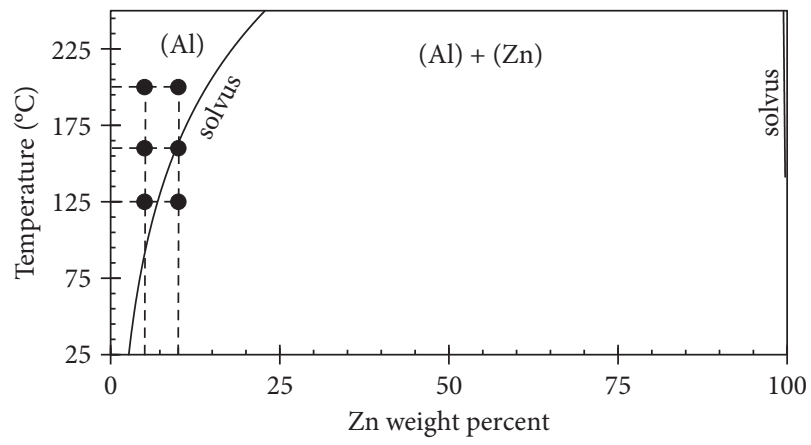

FIgUre 2: Partial Al-Zn phase diagram based on Chen and Chang's work [14] indicating the matrix nominal compositions and testing temperatures.

composites due to the high solubility of $\mathrm{Zn}$ in $\mathrm{Al}$, Al-rich solid solution ( $\alpha$ phase matrix of the composite) formed by redissolving $\mathrm{Zn}$ atoms following the partial $\mathrm{Al}-\mathrm{Zn}$ phase diagram is presented in Figure 2. A secondary Zn-rich $\beta$ phase is also present on the $\alpha$ phase grain boundary of the matrix [13]. According to the phase diagram, mostly the Alrich phase is present at the TMA temperatures used but the 


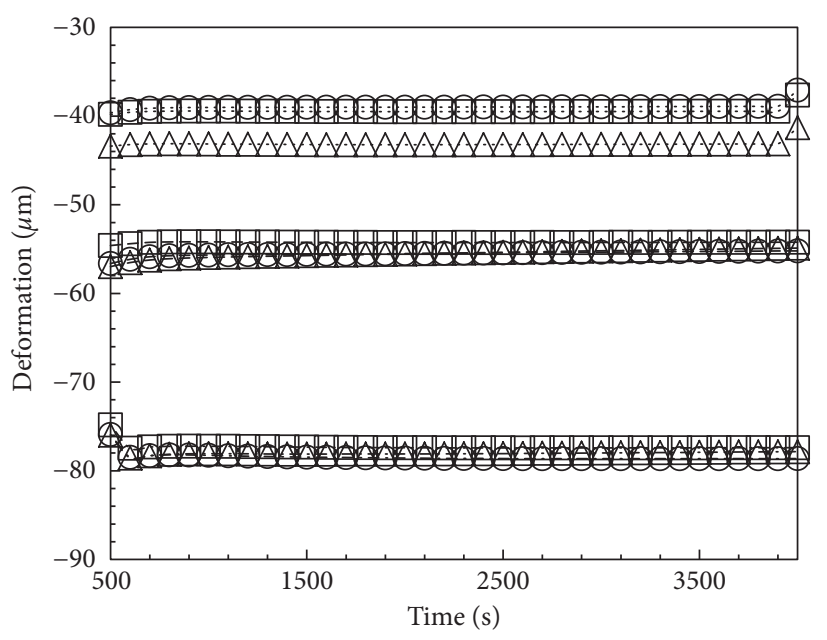

(a)

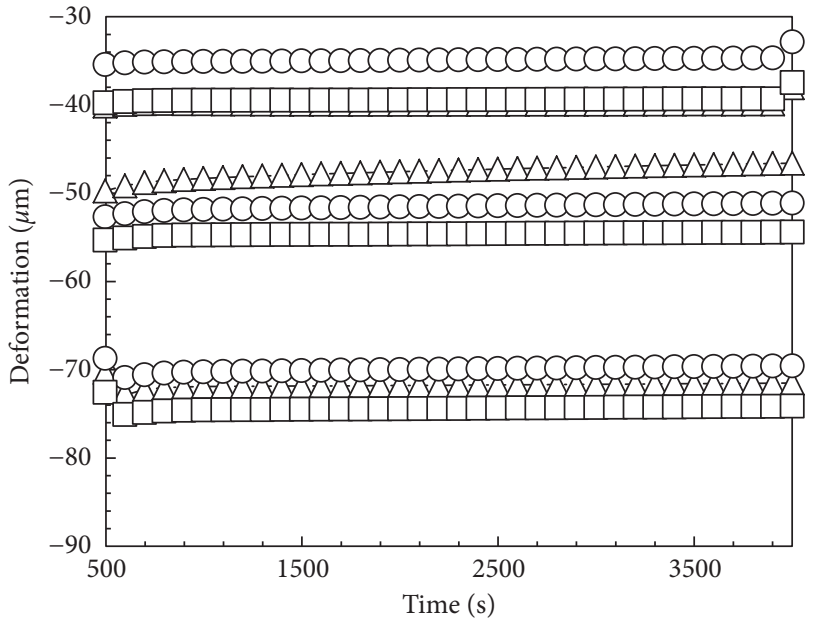

(b)

Figure 3: Typical Al-Zn matrix composite deformation curves at $125^{\circ} \mathrm{C}, 125^{\circ} \mathrm{C}$, and $125^{\circ} \mathrm{C}$ as a function of time for (a) 5 wt. $\% \mathrm{Zn}$ and (b) 10 wt. $\% \mathrm{Zn}$ (triangles $=0$ vol. $\% \mathrm{AlB}_{12}$, circles $=16.5$ vol. $\% \mathrm{AlB}_{12}$, and squares $=22.5$ vol. $\% \mathrm{AlB}_{12}$ ).

slow cooling process induced the zinc coarse precipitation because of the decreasing solid solubility of the aluminum matrix. The zinc-rich phase was precipitated on and near the grain boundary in these slowly cooled specimens (nearing equilibrium conditions). As it is well known, this coarse precipitation of an equilibrium secondary phase is not as efficient a hardening mechanism as the fine precipitation of metastable phases (i.e., those pertaining to artificial aging).

Moreover, as expected, after the annealing, that is, at room temperature, the composites' hardness increased with higher particle volume fractions. Such hardness improvement results from effective load transfer between the aluminum matrix and the reinforced $\mathrm{AlB}_{12}$ particles, as previously demonstrated in aluminum-based composites containing $\mathrm{B}_{4} \mathrm{C}$ particles $[15,16]$. $\mathrm{AlB}_{12}$ particles tend to organize themselves in clusters when surrounded by liquid aluminum, as indicated in previous works, attributed to the lack of sufficient mixing (stirring) when the matrix was molten [17]. The same behavior occurred in our experiments due to the short melting time upon sample fabrication. At the same time, for higher concentrations of $\mathrm{AlB}_{12}$ particles, optical microscopy barely revealed very small pores, which we attributed to the charge material used to incorporate the particles into the melt [10]. Upon loading the composite, those pores could induce crack nucleation near or on the particle/matrix interface. Nonetheless, for small porosity levels (as the one observed in the investigated composites), the detrimental effect on the strength of aluminum matrix composites may not be significant when the pores are associated with the hard reinforcements, as indicated by Ahmad et al. [18].

3.2. Thermomechanical Analysis. All as-cast samples were annealed for 20 minutes at $500^{\circ} \mathrm{C}$ and whereupon quenched in ice water before the TMA experiments. Figure 3 shows the deformation registered by the TMA for samples under compression as a function of time for the Al-5 wt.\% $\mathrm{Zn}$
TABLE 3: Deformation rate for the samples bearing $5 \mathrm{wt} . \% \mathrm{Zn}$ and 10 wt. $\%$ Zn.

\begin{tabular}{lccc}
\hline \multirow{2}{*}{${\text { Vol.\% } \mathrm{AlB}_{12}}$} & Temperature ${ }^{\circ} \mathrm{C}$ & \multicolumn{2}{c}{$\begin{array}{c}\text { Average deformation rate } \\
(\mu \mathrm{m} / \mathrm{s})\end{array}$} \\
& & $5 \mathrm{wt} . \% \mathrm{Zn}$ & $10 \mathrm{wt} \% \mathrm{Zn}$ \\
\hline \multirow{3}{*}{0} & 125 & $1.79 * 10^{-5}$ & $1.31 * 10^{-5}$ \\
& 160 & $4.10 * 10^{-4}$ & $6.63 * 10^{-4}$ \\
0.165 & 200 & $7.16 * 10^{-5}$ & $1.49 * 10^{-4}$ \\
\hline \multirow{3}{*}{0.225} & 125 & $7.89 * 10^{-5}$ & $1.65 * 10^{-4}$ \\
& 160 & $2.06 * 10^{-4}$ & $2.89 * 10^{-4}$ \\
& 200 & $-1.57 * 10^{-4}$ & $2.42 * 10^{-4}$ \\
\hline & 125 & $1.71 * 10^{-5}$ & $8.73 * 10^{-5}$ \\
& 160 & $7.08 * 10^{-6}$ & $1.42 * 10^{-4}$ \\
& 200 & $-8.38 * 10^{-5}$ & $1.41 * 10^{-4}$ \\
\hline
\end{tabular}

(Figure 3(a)) and Al-10 wt.\% Zn (Figure 3(b)) composites containing $0,16.5$, and 22.5 vol.\% $\mathrm{AlB}_{12}$ up to one-hour annealing at $125^{\circ} \mathrm{C}, 160^{\circ} \mathrm{C}$, and $200^{\circ} \mathrm{C}$, respectively. The $5 \mathrm{wt}$. $\% \mathrm{Zn}$ samples underwent smaller deformations for higher particle volume fraction at all treating temperatures and higher deformation for samples with no particle volume fraction. Counterintuitively, the $10 \mathrm{wt} \% \mathrm{Zn}$ composite bearing the higher particle volume fraction underwent a greater deformation at all temperatures, that is, $125^{\circ} \mathrm{C}$, $160^{\circ} \mathrm{C}$, and $200^{\circ} \mathrm{C}$. Samples with 16.5 vol. $\% \mathrm{AlB}_{12}$ registered the lowest deformation for the $10 \mathrm{wt} . \%$ zinc. Naturally, for higher temperatures, the $\mathrm{Al}-\mathrm{Zn}$ matrix is softened in all samples (higher negative deformation) at the beginning of the TMA experiment. Yet, as time progressed, those deformations decreased mostly for all samples, as shown in Table 3 . These seemingly discrepant results are analyzed later in this section. At this point, we deem noteworthy to mention that these TMA experiments did not activate a creep behavior from any of the tested composites. In effect, the temperatures and load used are not enough for the onset 
TABLE 4: Linear regression parameters.

\begin{tabular}{lccc}
\hline $\begin{array}{l}\text { Fitted } \\
\text { parameters }\end{array}$ & Value & $\begin{array}{c}\text { Standard errors of the } \\
\text { parameters }\end{array}$ & $\begin{array}{c}p \\
\text { value }\end{array}$ \\
\hline$a_{0}$ & 11.8979 & 2.1990 & 0.000 \\
$a_{1}$ & 1.3054 & 0.1912 & 0.000 \\
$a_{2}$ & 1.6627 & 0.5620 & 0.005 \\
$a_{12}$ & -0.2389 & 0.0711 & 0.002 \\
$a_{3}$ & -0.4780 & 0.0098 & 0.000 \\
\hline
\end{tabular}

of creep. In effect, a previous work with $\mathrm{Al}-\mathrm{Cu}$ matrix composites reinforced with diboride particles assessed the creep behavior and the corresponding mechanisms at greater temperatures and applied stresses [19].

A multiple linear regression analysis of the experimental data permitted to create a predictive model of the deformation using the Minitab statistical package. The regression model fitted is shown in (3), and Table 4 displays the fitted parameters. The deformation (in $\mu \mathrm{m}$ ) used as a response variable for the model was the maximum deformation difference measured between 500 seconds and 3,600 seconds of the TMA:

$$
\text { Deformation }(\mu \mathrm{m})=a_{0}+a_{1} \mathrm{Zn}+a_{2} B+a_{12} \mathrm{Zn} B+a_{3} T \text {, }
$$

where $a_{0}, a_{1}, a_{2}, a_{12}$, and $a_{3}$ are the fitted regression parameters; $B$ is the boron weight percentage, $T$ is the temperature in ${ }^{\circ} \mathrm{C}$, and $\mathrm{Zn}$ is the zinc weight percent. The selection of the boron weight percent rather than the $\mathrm{AlB}_{12}$ amount as an independent variable will become apparent in the next paragraphs.

For the fitted model in (3), the very high computed correlation coefficient, that is, $R^{2}=0.98$, demonstrates the predicting effectiveness of the model. Additionally, the low $p$ values of all fitted parameters indicate that these predictors are all meaningful parts of the model because their eventual changes do effect the response variable. The equation quantifies how the presence of $\mathrm{Zn}$ and dodecaboride particles actually increased the compression deformation for every temperature, that is, softening the matrix. As shown in the fitted model, the individual presence of zinc and boron increased the negative (compression) deformation, that is, $a_{1}>0$ and $a_{2}>0$. On the other hand, the interaction between both elements $\left(a_{12}<0\right)$ reduced the deformation of the composite. The model also indicates, as expected, that temperature is an important factor in holding back the compressive deformation $\left(a_{3}<0\right)$. This negative value indicates that temperature is in reality strengthening the aluminum matrix. The phase diagram in Figure 2 can explain this seemingly contradictory finding. The treatment temperatures indicate that $\mathrm{Zn}$ has redissolved into the $\alpha \mathrm{Al}$ phase, which led to solid solution strengthening of the matrix. Further analysis of the TMA curves corroborates the fitted model where the slopes of the deformation as a function of time are positive indicating a decrease of deformation with respect to time as shown in Table 3.
Further analysis of the micrographs showed the formation of $\mathrm{AlB}_{2}$ particles nearby $\mathrm{AlB}_{12}$ particles for both concentrations of zinc, as shown in Figure 4 for $5 \mathrm{wt} . \% \mathrm{Zn}$ (Figure 4(a)) and 10 wt.\% Zn (Figure 4(b)). The small amount of diboride particles could not be quantified and is estimated in less than 1 vol.\%. On the contrary, when $\mathrm{Zn}$ is not present in the matrix, such transformation of the borides particles was not observed. In effect, another study involving Al-based composites revealed that $\mathrm{Mg}$ acting as alloying element of the matrix triggered a transformation of the dodecaboride particles. In that case, magnesium induced the decomposition of $\mathrm{AlB}_{12}$ into $\mathrm{Al}_{x} \mathrm{Mg}_{1-x} \mathrm{~B}_{2}$ [20]. Therefore, the presence of $\mathrm{AlB}_{2}$ suggests that zinc favored the $\mathrm{AlB}_{12}$ to $\mathrm{AlB}_{2}$ transformation, which somehow might have lowered the strength of the matrix at high temperatures as demonstrated for $10 \mathrm{wt} . \% \mathrm{Zn}$ where the deformation is greater for samples bearing higher particle volume fraction. As demonstrated by Deppisch et al. [21], by fast cooling the alloy below $1000^{\circ} \mathrm{C}$, nucleation of $\mathrm{AlB}_{12}$ can be avoided and $\mathrm{AlB}_{2}$ phase can be nucleated within the alloy. However, the contrary occurs with our samples. By allowing a slow cooling after the TMA analysis, high nucleation of $\mathrm{AlB}_{12}$ is present with some regions nucleated with $\mathrm{AlB}_{2}$. A prior research suggested that the addition of large sized particles may increase the composite ductility [6] at high temperatures, as shown in Figure 3. The presence of the $\mathrm{AlB}_{12}$ particles and the addition of zinc into the Al-Zn matrix are inducing a strengthening of the composite matrix, as the deformation decreased for increasing concentration of zinc and boron at high temperatures, as demonstrated in the regression model.

3.3. Brinell Hardness. As mentioned, Brinell hardness (HB) was performed on the samples after they underwent the TMA experiments; this means that the specimens had been slowly cooled (similar to an annealing process) prior to the hardness tests. The Brinell hardness results in Figure 5 demonstrate how zinc concentration hardened the material after zinc precipitation upon the annealing process, following equilibrium conditions, as shown in the $\mathrm{Al}-\mathrm{Zn}$ phase diagram in Figure 2. Naturally, HB also increased for higher dodecaboride volume fractions. The average $\mathrm{HB}$ values for samples bearing $5 \mathrm{wt} \% \mathrm{Zn}$ were $0.158 \mathrm{GPa}$, $0.184 \mathrm{GPa}$, and $0.218 \mathrm{GPa}$ for $0,0.165$, and $0.225 \mathrm{vol} . \%$ $\mathrm{AlB}_{12}$, respectively. Samples containing $10 \mathrm{wt} \% \mathrm{Zn}$ obtained $\mathrm{HB}$ values of $0.624 \mathrm{GPa}, 0.675 \mathrm{GPa}$, and $0.761 \mathrm{GPa}$, for $0,0.165$, and 0.225 vol. $\% \mathrm{AlB}_{12}$, respectively. These results demonstrate that the material can achieve greater hardness values with the combined addition of $\mathrm{Zn}$ as the alloying element of the matrix and the dodecaboride particles as reinforcement at room temperature. Because the dodecaboride particles have higher stiffness than that of the $\mathrm{Al}$ matrix, dodecaboride particles produced a constraint resulting in a reduction of plastic deformation of the matrix when $\mathrm{HB}$ was performed. As a result, the deformation under compression lowered, which $\mathrm{i}$ indicated by a hardness increment. 


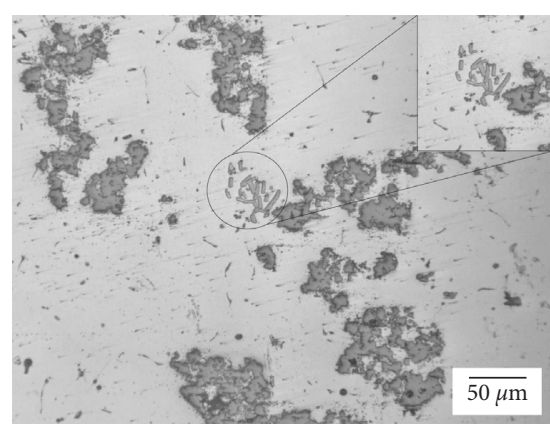

(a)

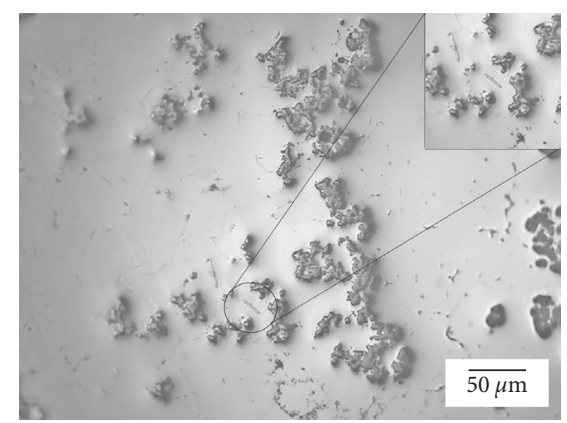

(b)

Figure 4: $\mathrm{AlB}_{2}$ particles' presence in the composites with (a) 5 wt.\% $\mathrm{Zn}$ and (b) $10 \mathrm{wt} . \% \mathrm{Zn}$.

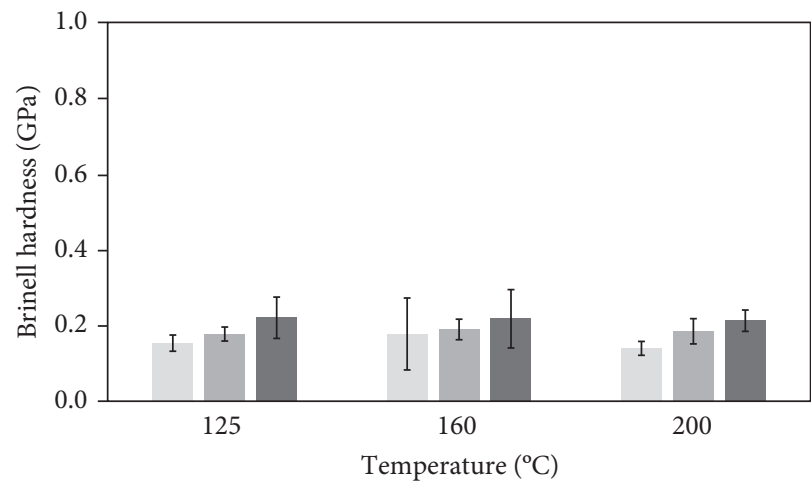

(a)

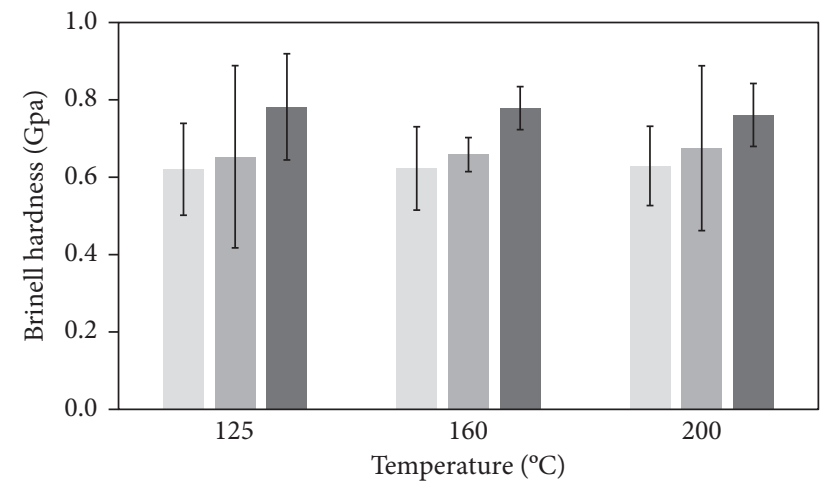

(b)

Figure 5: Brinell hardness after TMA for 0 wt.\% B (light gray), 2.08 wt.\% B (light-dark gray), and 4.17 wt.\% B (dark gray) at $125^{\circ} \mathrm{C}, 160^{\circ} \mathrm{C}$, and $200^{\circ} \mathrm{C}$ for (a) 5 wt.\% $\mathrm{Zn}$ and (b) 10 wt.\% $\mathrm{Zn}$.

\section{Discussion}

A recent publication proposed a model of grain boundary(GB-) assisted second phase formation on primary aluminum solid solutions [22], based on a foundational work by Cahn [23]. The transformation temperatures are similar to those used in the TMA study of the present research. In a prior research similar transformation temperatures were reported as the authors found that as the temperature fell, so did $\theta$, with $\theta$ being the contact angle (dihedral or wetting angle). Figure 6 presents schematically the formation of the $\mathrm{Zn}$-rich $\beta$ phase (allotriomorphic phase) in the (Al)/(Al) GB with the corresponding dihedral $\theta$ angle indicated. In the works by Kogtenkova et al. [24] and Straumal et al. [22, 25], for lower temperatures, that is, $125^{\circ} \mathrm{C}$ (as in our TMA lower temperature experiments), the dihedral angle becomes zero. This translates into the formation of a thin film of $\beta$ phase in the GB, which become a virtual $\mathrm{Zn}$ sink via lattice diffusion but mostly from GB diffusion. In other words, at lower annealing temperatures, GB diffusion should prevail, leading to dihedral angles nearing zero.

However, in the presence of large irregular particles (as in the present research), the situation becomes more complicated. In particular, aluminum borides are known to have catalytic properties as heterogeneous nucleation sites of primary $\alpha \mathrm{Al}$ phase (Al) in aluminum alloys' solidification.

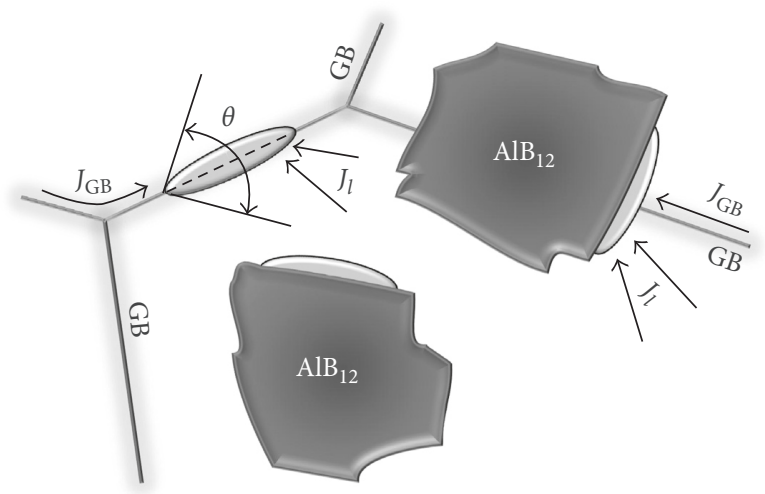

FIGURE 6: Schematic of the formation of $\beta$ allotriomorphs on the grain boundaries (GB) with the contact angle $\theta$ indicated and two possible loci of the $\mathrm{AlB}_{12}$ particles with incipient heterogeneous $\beta$ crystallization. Potential diffusion paths via lattice diffusion $\left(J_{l}\right)$ and grain boundary diffusion $\left(J_{\mathrm{GB}}\right)$ are also depicted.

Such catalytic potency is attributed to small disregistry (or mismatch) between low Miller index planes of the boride, and atomic planes of the aluminum nuclei. The precipitated Zn-rich allotriomorphs bearing the said pseudowetting feature could have also formed in the $\mathrm{AlB}_{12} /(\mathrm{Al})$ interface (Figure 6). There are important reasons that could cause 
such heterogeneous crystallization, one being the strain caused by the differences in coefficient of thermal expansion between the dodecaboride and the aluminum phase. Such strain can be relieved by the formation of new phase on the interface, lowering the overall Gibbs free energy of the material. Unfortunately, the micrographs in Figures 1 and 4 could not be taken at higher magnification and could not prove this potential effect. Nonetheless, the lowest row of micrographs in Figure 1 and the image in Figure 4(b) present a slightly observable feature: the formation of the null wetting angle in the $\beta /(\mathrm{Al})$ interface. As a consequence, small volume fractions of $\beta$ phase appear delineating the (Al) grain, as $(\mathrm{Zn})$ formed in the ( $\mathrm{Al})$ grain boundaries, as predicted by Cahn.

Once again, one should be careful in analyzing this phenomena independently from the presence of the $\mathrm{AlB}_{12}$ particle. Such $\mathrm{Zn}$-dodecaboride interactivity is manifest in the thermomechanical properties studied in the present work and has been further revealed by the noticeable effect of the interaction term in the fitted model in (3). This relationship between microstructure and mechanical properties (or strain) requires a further in-depth study with transmission electron microscopy that is beyond the scope of the present research.

As a whole, the outcome of this experimentation provides a baseline of research for this novel composite. It became evident that it is not enough the addition of dodecaboride particles to formulate a high strength composite if a heat treatable aluminum matrix is used. Not only the amount of dodecaboride particles and the presence of zinc but also the conditions of the treatment and the ensuing cooling rate should be taken into consideration if these particles are to be used as reinforcements for applications at room temperature.

\section{Conclusions}

The effect of the addition of $\mathrm{AlB}_{12}$ particles to gravity cast $\mathrm{Al}$ $\mathrm{Zn}$ alloys was studied and related to the composite deformation at high temperature. Deformation of the Al-5 wt. $\% \mathrm{Zn}$ and $\mathrm{Al}-10 \mathrm{wt} . \% \mathrm{Zn}$ matrix composites decreased as a function of time for mostly all temperatures during treatments at $125^{\circ} \mathrm{C}, 160^{\circ} \mathrm{C}$, and $200^{\circ} \mathrm{C}$ with the addition of $\mathrm{AlB}_{12}$ particles. Brinell hardness after thermomechanometric studies and simulated annealing increased as a function of the $\mathrm{AlB}_{12}$ particle volume fraction for both $\mathrm{Zn}$ concentrations studied. Samples bearing higher $\mathrm{Zn}$ levels had higher Brinell hardness due to matrix solid solution strengthening at the temperatures studied. Coarse zinc precipitation in the equilibrium secondary phase occurred for all concentrations and temperatures studied as a result of the slow cooling process after thermomechanical studies were carried out. A multiple linear regression model quantifies the deformation for different temperatures, boron, and zinc levels for these composites. When the influences of zinc and boron (forming aluminum dodecaboride) are considered individually in the predictive model, one can observe that both elements contribute to increase the compression deformation of the composite. However, the model suggests that the interaction between both elements reduce this deformation.

\section{Disclosure}

This work was previously presented in part at The Minerals Metal and Materials Society Annual Meeting and Exhibition 2016 in Nashville, Tennessee, USA.

\section{Conflicts of Interest}

The authors declare that there are no conflicts of interest regarding the publication of this paper.

\section{Acknowledgments}

This material is based upon work supported by the United States National Science Foundation under Grant nos. HRD 0833112 and HRD 1345156 (CREST program).

\section{References}

[1] H. E. Calderón, R. G. I. Hidalgo, Z. H. Melgarejo, and O. M. Suárez, "Effect of $\mathrm{AlB}_{2}-\mathrm{Mg}$ interaction on the mechanical properties of Al-based composites," Materials Science and Engineering: A, vol. 527, no. 9, pp. 2258-2264, 2010.

[2] Z. H. Melgarejo, O. M. Suárez, and K. Sridharan, "Microstructure and properties of functionally graded $\mathrm{Al}-\mathrm{Mg}-\mathrm{B}$ composites fabricated by centrifugal casting," Composites Part A: Applied Science and Manufacturing, vol. 39, no. 7, pp. 1150-1158, 2008.

[3] T. Dursun and C. Soutis, "Recent developments in advanced aircraft aluminium alloys," Materials and Design, vol. 56, pp. 862-871, 2014.

[4] S. A. Sajjadi, H. R. Ezatpour, and M. Torabi-Parizi, "Comparison of microstructure and mechanical properties of A356 aluminum alloy $/ \mathrm{Al}_{2} \mathrm{O}_{3}$ composites fabricated by stir and compocasting processes," Materials and Design, vol. 34, pp. 106-111, 2012.

[5] C. Bacciarini and V. Mathier, "Aluminium AA6061 matrix composite reinforced with spherical alumina particles produced by infiltration: perspective on aerospace applications," Journal of Metallurgy, vol. 2014, Article ID 248542, 10 pages, 2014.

[6] M. Corchado, F. Reyes, and O. M. Suárez, "Effects of $\mathrm{AlB}_{2}$ particles and zinc on the absorbed impact energy of gravity cast aluminum matrix composites," JOM, vol. 66, no. 6, pp. 926-934, 2014.

[7] Z. H. Melgarejo, P. J. Resto, D. S. Stone, and O. M. Suárez, "Study of particle-matrix interaction in $\mathrm{Al} / \mathrm{AlB}_{2}$ composite via nanoindentation," Materials Characterization, vol. 61, no. 2, pp. 135-140, 2010.

[8] H. E. Calderón, O. M. Suárez, and E. Barrios, "Thermomechanical effects on aluminum matrix composites reinforced with $\mathrm{AlB}_{2}$ particles," Journal of Composite Materials, vol. 42, no. 25, pp. 2651-2672, 2008.

[9] Z. Boumerzoug and M. Fatmi, "Effect of heat treatments on discontinuous precipitation kinetics in Al-30 wt.\% Zn alloy," Materials Characterization, vol. 60, no. 8, pp. 768-774, 2009.

[10] T. K. Adelakin, "An experimental study of aluminum boride particles distribution in centrifugal cast $\mathrm{Al} / \mathrm{AlB}_{x}$ composites," 
M.Sc. thesis, Mechanical Engineering, University of Puerto Rico, Mayagüez, PR, USA, 2009.

[11] S. Shan, X. Chen, Z. Xi, X. Yu, X. Qu, and Q. Zhang, "The effect of nitrile-functionalized nano-aluminum oxide on the thermomechanical properties and toughness of phthalonitrile resin," High Performance Polymers, vol. 29, no. 1, pp. 113-123, 2017.

[12] B. Liu, Y. P. Li, H. Matsumoto et al., "Thermomechanical response of particulate-reinforced powder metallurgy titanium matrix composites-A study using processing map," Materials Science and Engineering: A, vol. 527, no. 18-19, pp. 4733-4741, 2010.

[13] G. A. López, E. J. Mittemeijer, and B. B. Straumal, "Grain boundary wetting by a solid phase; microstructural development in a $\mathrm{Zn}-5$ wt.\% Al alloy," Acta Materialia, vol. 52, no. 15, pp. 4537-4545, 2004.

[14] S. L. Chen and Y. A. Chang, "A thermodynamic analysis of the Al-Zn system and phase diagram calculation," Calphad, vol. 17, no. 2, pp. 113-124, 1993.

[15] J. Oñoro, M. D. Salvador, and L. E. G. Cambronero, "Hightemperature mechanical properties of aluminum alloys reinforced with boron carbide particles," Materials Science and Engineering: A, vol. 499, no. 1-2, pp. 421-426, 2009.

[16] O. Torabi and R. Ebrahimi-Kahrizsangi, "Synthesis of $\mathrm{B}_{4} \mathrm{C}$, $\mathrm{Al}_{2} \mathrm{O}_{3}$, and $\mathrm{AlB}_{12}$ reinforced $\mathrm{Al}$ matrix nano composites via mechanochemical method," Journal of Composite Materials, vol. 46, no. 18, pp. 2227-2237, 2012.

[17] L. Yuan, J. Han, J. Liu, and Z. Jiang, "Mechanical properties and tribological behavior of aluminum matrix composites reinforced with in-situ $\mathrm{AlB}_{2}$ particles," Tribology International, vol. 98, pp. 41-47, 2016.

[18] S. N. Ahmad, J. Hashim, and M. I. Ghazali, "The effects of porosity on mechanical properties of cast discontinuous reinforced metal-matrix composite," Journal of Composite Materials, vol. 39, no. 5, 2005.

[19] O. M. Suárez, N. Cortes-Urrego, S. Soto-Medina, and D. Marty-Flores, "High-temperature mechanical behavior of Al-Cu matrix composites containing diboride particles," Science and Engineering of Composite Materials, vol. 21, no. 1, pp. 29-38, 2014.

[20] T. K. Adelakin and O. M. Suárez, "Study of casting parameters and magnesium effects on the distribution of boride particles during centrifugal casting of functionally graded aluminum matrix composite," Science and Engineering of Composite Materials, vol. 17, no. 3, pp. 155-172, 2010.

[21] C. Deppisch, G. Liu, A. Hall et al., "The crystallization and growth of $\mathrm{AlB}_{2}$ single crystal flakes in aluminum," Journal of Materials Research, vol. 13, no. 12, pp. 3485-3498, 1998.

[22] B. B. Straumal, A. A. Mazilkin, and B. Baretzky, "Grain boundary complexions and pseudopartial wetting," Current Opinion in Solid State and Materials Science, vol. 20, no. 5, pp. 247-256, 2016.

[23] J. W. Cahn, "Critical point wetting," Journal of Chemical Physics, vol. 66, no. 8, pp. 3667-3672, 1977.

[24] O. A. Kongtenkova, P. Zieba, T. Czeppe, L. Litynska-Dobrzynska, B. B. Straumal, and A. N. Nekrasov, "Wetting of grain boundaries by the second solid phase in Al based alloys," Bulletin of the Russian Academy of Sciences: Physics, vol. 77, no. 11, pp. 1386-1390, 2013.

[25] B. B. Straumal, B. Baretzky, O. A. Kogtenkova, A. B. Straumal, and A. S. Sidorenko, "Wetting of grain boundaries in Al by the solid $\mathrm{Al}_{3} \mathrm{Mg}_{2}$ phase," Journal of Materials Science, vol. 45, pp. 2057-2061, 2010. 


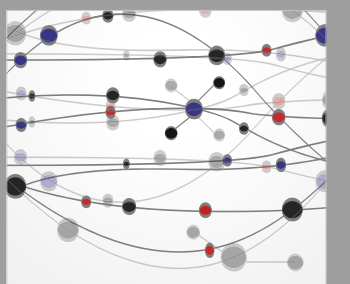

The Scientific World Journal
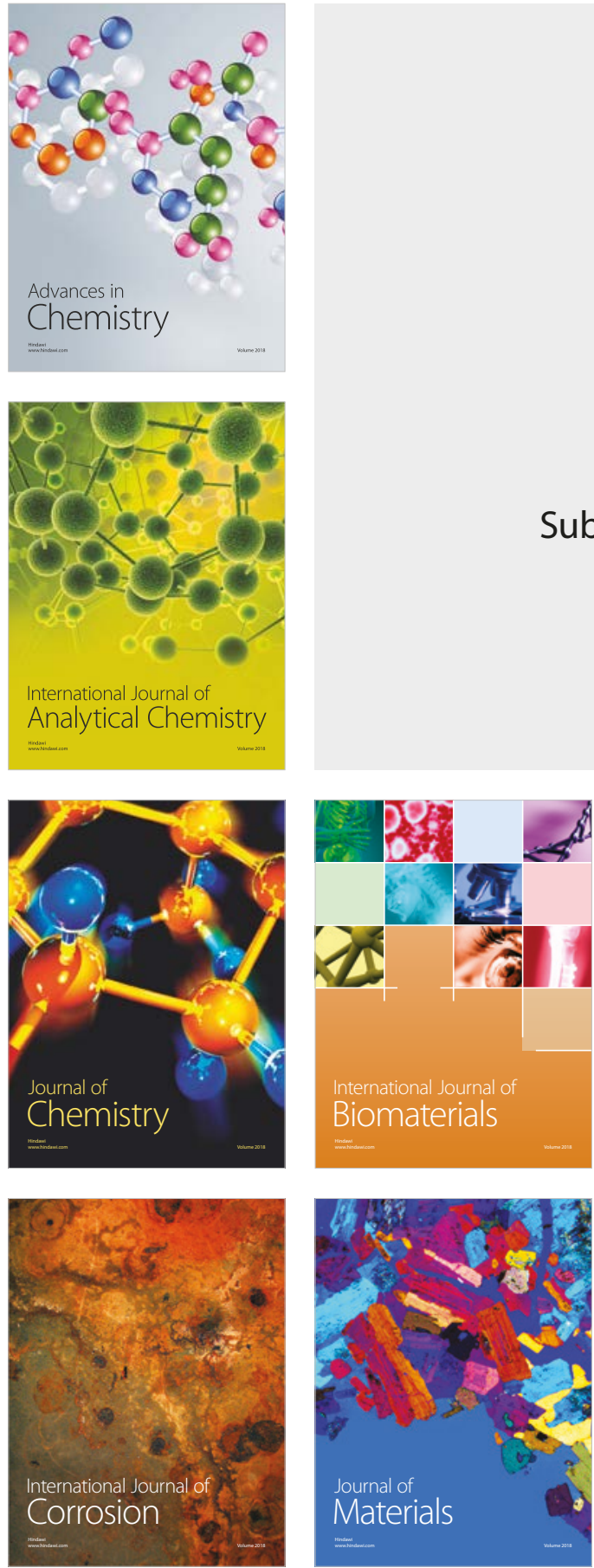

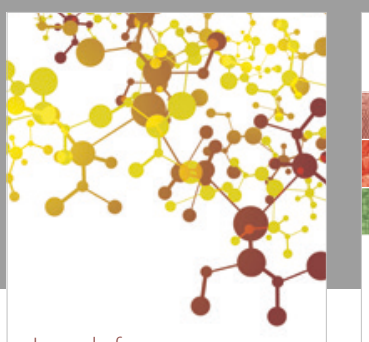

Journal of

Applied Chemistry
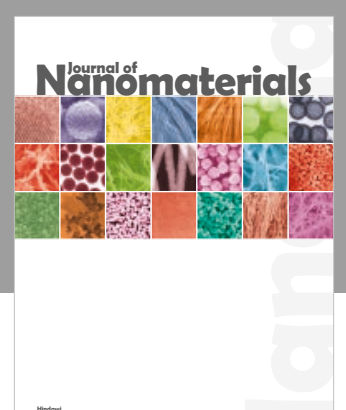

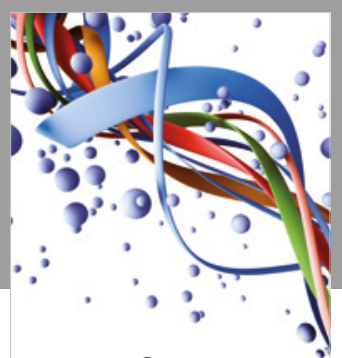

Scientifica

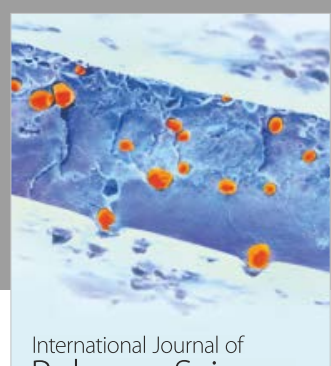

Polymer Science

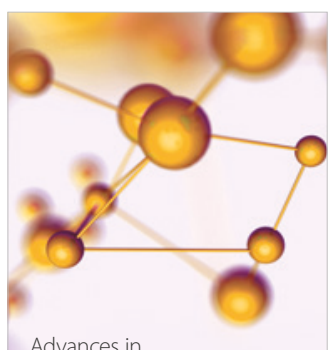

Physical Chemistry
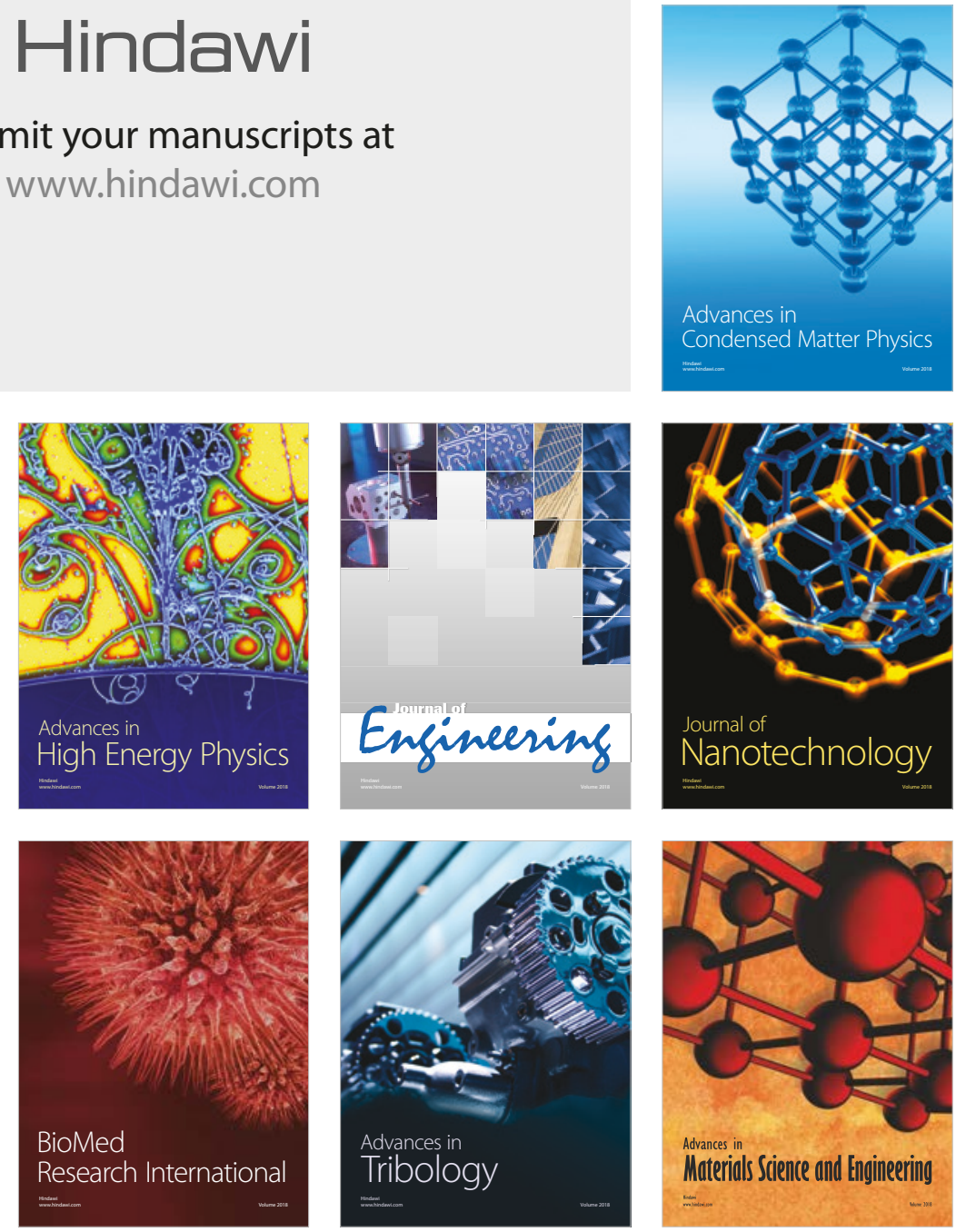